\title{
EVALUATION OF THE EFFECTS OF NUTRITIONAL INTERVENTION MEASURES ON SAM CHILDREN IN A NUTRITIONAL REHABILITATION CENTRE, ACSR GOVERNMENT MEDICAL COLLEGE, NELLORE, A. P.
}

\author{
Cherukuri Nirmala1 ${ }^{1}$ Rapaka Varalaxmi², Moturi Ratnamanjula 3 , Chinta Lakshmi Prasanna ${ }^{4}$, MVS Nagaraju $^{5}$ \\ ${ }^{1}$ Associate Professor, Department of Paediatrics, ACSR Government Medical College, Nellore. \\ ${ }^{2}$ Medical Officer, NRC, GGH, Nellore. \\ ${ }^{3}$ Associate Professor, Department of Paediatrics, ACSR Government Medical College, Nellore. \\ ${ }^{4}$ Assistant Professor, Department of Paediatrics, ACSR Government Medical College, Nellore. \\ 5 Senior Resident, Department of Community Medicine, Kurnool Medical College.
}

ABSTRACT

\section{BACKGROUND}

Malnutrition among children is widely prevalent in developing countries including India. More than 33\% of deaths in children less than 60 months of age are associated with malnutrition. ${ }^{1}$ To reduce the mortality and morbidity among children with severe acute malnutrition, the government has established nutritional rehabilitation centres across India in the districts and in the teaching medical colleges. A study was done at ACSR Govt. Medical College to analyse the effects of nutritional interventions on SAM children in a facility based Nutritional Rehabilitation Centre.

\section{MATERIALS AND METHODS}

A retrospective longitudinal analysis of case records was done, to assess the outcome of nutritional intervention measures among children with severe acute malnutrition admitted to a 20 bedded NRC. As it was a retrospective study and the data was collected from the medical records, there were no exclusion criteria. All the children with SAM admitted in the paediatric department and managed in NRC were included in the study. The data collected was entered in Microsoft Excel Sheet and analysed using MS Excel 2010 and SPSS Version 21. Statistical tests, t-test was applied wherever needed.

\section{RESULTS}

All children admitted in an NRC at the Govt. General Hospital/ACSR Govt. Medical College were included in the study. Children in the age group of 12-23 months were more commonly affected. The proportion of females (52.17\%) among the admitted children was greater than that of males (47.83\%). A statistically significant difference was found between mean weight at admission and mean weight at discharge for all children ( $t=-11.572 ; \mathrm{p}<0.001)$, for males it was $\mathrm{t}=-8.094 ; \mathrm{p}<0.001$ and for females $\mathrm{t}=-8.257$; $\mathrm{p}<0.001$. A statistically significant difference was found between mean weight at admission and mean weight at discharge for all children who stayed in NRC for a week and more. The duration of stay was for 14 days in $11 \%$ of the children, whereas $33 \%$ of them had a stay between 8-14 days.

\section{CONCLUSION}

Nutritional rehabilitation centre has an impact on improving the nutritional status of SAM children. To improve the utilisation of the NRC services, there should be better coordination and communication between the health workers and the staff of NRC units. Further, the SAM child should be followed up in the community, if there is noncompliance for followup visits in NRC. Though the stay at NRC is for 14 days ideally, in practice it does not find favour among the parents who happen to be from the low socioeconomic group. Once the medical complications are managed with and the appetite of the child improves, shifting these children to a community based programme may go a long way in motivating parents to propagate and utilise services of NRC.

\section{KEYWORDS}

Severe Acute Malnutrition, Weight Gain, Nutritional Rehabilitation, Duration, Outcome.

HOW TO CITE THIS ARTICLE: Nirmala C, Varalaxmi R, Ratnamanjula M, et al.Evaluation of the effects of nutritional intervention measures on SAM children in nutritional rehabilitation centre, ACSR Government Medical College, Nellore, A. P. J. Evolution Med. Dent. Sci. 2016;5(87):6443-6446, DOI: 10.14260/Jemds/2016/1458

\section{BACKGROUND}

Nutrition is important for the growth and development of the child. Anthropometry is used to assess the nutritional status of

Financial or Other, Competing Interest: None.

Submission 28-09-2016, Peer Review 22-10-2016,

Acceptance 24-10-2016, Published 28-10-2016.

Corresponding Author:

Dr. Cherukuri Nirmala,

Flat No.3, Esteem Villa, Behind Bhavan's School,

Vivekanandapuram North, Sainikpuri,

Secunderabad-500094

Telangana, India.

E-mail: cnirmala06@yahoo.com

DOI: $10.14260 / \mathrm{jemds} / 2016 / 1458$ children as it is easy, inexpensive and accurate. The anthropometric indices include weight for age, height/length for age and weight for height/length. Underweight, based on weight-for-age, is a composite measure of stunting and wasting and is recommended as the indicator to assess changes in the magnitude of malnutrition over time. Underweight is often used as an indicator of the nutritional status of a population's health. ${ }^{1}$ Wasting is indicative of current or acute malnutrition resulting from inadequate food intake, incorrect feeding practices and shows marked seasonal patterns associated with changes in food availability or disease prevalence to which it is very sensitive.

Based on the severity, acute malnutrition is classified into severe acute malnutrition and moderate acute malnutrition. 
Global estimates indicate that there are nearly 20 million children who are severely acutely malnourished. ${ }^{2}$ In India, as per the National Family Health survey III, about $6.4 \%$ of children under 60 months of age are suffering from severe acute malnutrition and about $43 \%$ of children are underweight. 3 To combat this problem under National Health Mission, 896 Nutrition Rehabilitation Centres (NRCs) are started in our country and among these, 30 NRCs are in Andhra Pradesh. They provide nutritional rehabilitation to the children suffering from SAM \& its complications. ${ }^{4}$

To reduce the mortality and morbidity among these children, nutritional rehabilitation centres were started by the Government of India in the year 2011. There were certain guidelines for management of these children at facility and community level. ${ }^{1}$ The present study was done to identify the effect of nutritional interventions and duration taken for weight gain among the children admitted to NRC.

\section{MATERIALS AND METHODS}

All children fulfilling the criteria for diagnosing SAM admitted to the NRC and paediatric unit were included in the study. As it was a retrospective study and the data collected from the medical records, there were no exclusion criteria. The study period was from January 2013 to December 2014. The criteria for diagnosing SAM are (a) weight-for-height or weight for length $<-3$ SD of the median WHO child growth standards and/or (b) bilateral pitting oedema and/or (c) mid-upper-arm circumference $<115 \mathrm{~mm} /$ by visible severe wasting. The data was collected from the medical records and the registers of the NRC and Paediatric Department of Govt. General Hospital/ACSR GMC, Nellore. It is a retrospective study. All the children meeting the criteria of SAM were enrolled and the age, sex, weight at admission, weight at discharge were recorded and analysed. The SAM children were managed as per the guidelines of the facility based care of SAM children by MOHFW, GOI. In the initial phase of stabilisation, the complications are identified and the children were managed accordingly. All SAM children were started on antibiotics as per the protocol based on the diagnosis. All the children were given micronutrient supplementation during their stay. They were given therapeutic starter diet F75 and catch up diet F100 feeds in the stabilisation and transition phases respectively, either oral or through orogastric tube based on the general condition of the child. They were monitored closely. For older children, solid feeds that include khichri, dal rice and halwa were added to the diet. For infants less than 6 months, supplementary suckling technique was tried. There were no recorded cases of SAM with oedema. The data collected was entered in Microsoft Excel Sheet and analysed using MS Excel 2010 and SPSS Version 21. Statistical tool t-test was applied wherever needed.

\section{RESULTS}

About 345 children were admitted to the NRC. The age and sex distribution were analysed as noted in table 1 . The children were distributed into various age groups. Majority (36.23\%) of the children were in the age group of 13-24 months, followed by children in the age group of 25-36 months $(17.68 \%)$ and less than 6 months (17.68\%) respectively. Comparison of gender distribution revealed that SAM was more common among female children $(52.17 \%)$ than male children (47.83\%) suggestive of gender inequality.

\begin{tabular}{|c|c|c|c|}
\hline Age Group & Males & Females & Total (\%) \\
\hline $0-6$ months & 28 & 33 & $61(17.68)$ \\
\hline $\begin{array}{c}\text { 7-12 } \\
\text { months }\end{array}$ & 18 & 40 & $58(16.81)$ \\
\hline $\begin{array}{c}13-24 \\
\text { months }\end{array}$ & 66 & 59 & $\begin{array}{c}125 \\
(36.23) \\
\end{array}$ \\
\hline $\begin{array}{c}25-36 \\
\text { months }\end{array}$ & 33 & 28 & $61(17.68)$ \\
\hline $\begin{array}{c}37-48 \\
\text { months }\end{array}$ & 15 & 16 & 31 (8.99) \\
\hline $\begin{array}{c}49-60 \\
\text { months }\end{array}$ & 5 & 4 & $9(2.61)$ \\
\hline Total & $\begin{array}{c}165 \\
(47.83 \%)\end{array}$ & $\begin{array}{c}180 \\
(52.17 \%)\end{array}$ & $345(100)$ \\
\hline \multicolumn{4}{|c|}{$\begin{array}{l}\text { Table 1. Distribution of Study Participants According to } \\
\text { Age and Gender }\end{array}$} \\
\hline
\end{tabular}

Data analysis based on the weight on admission and discharge has shown that there is a definite increase in the weight among the children at NRC, irrespective of the age and sex as noted in table 2. Overall mean weight at admission was $6.72 \pm 2.31 \mathrm{~kg}$. For males, it was $7.14 \pm 2.41 \mathrm{~kg}$ and for females, it was $6.34 \pm 2.15 \mathrm{~kg}$. The overall mean weight at discharge is $6.93 \pm 2.32 \mathrm{~kg}$. For males, it was $7.35 \pm 2.43 \mathrm{~kg}$ and for females, it was $6.55 \pm 2.15 \mathrm{~kg}$. A statistically significant difference was found between mean weight at admission and mean weight at discharge for all children ( $\mathrm{t}=-11.572 ; \mathrm{p}<0.001)$, for males it was $\mathrm{t}=-8.094 ; \mathrm{p}<0.001$ and for females $\mathrm{t}=-8.257$; $\mathrm{p}<0.001$.

\begin{tabular}{|c|c|c|c|c|c|c|}
\hline \multirow{2}{*}{$\begin{array}{c}\text { Age Group } \\
\text { (Months) }\end{array}$} & \multicolumn{3}{|c|}{ Mean Weight at Admission (Kg) } & \multicolumn{2}{c|}{ Mean Weight at Discharge (Kg) } \\
\cline { 2 - 7 } & Males & Females & Total & Males & Females & Total \\
\hline $0-6$ & $3.77 \pm 1.32$ & $3.22 \pm 1.004$ & $3.47 \pm 1.18$ & $3.99 \pm 1.31$ & $3.48 \pm 1.01$ & $3.71 \pm 1.17$ \\
\hline $7-12$ & $6.26 \pm 0.88$ & $5.49 \pm 0.87$ & $5.73 \pm 0.94$ & $6.46 \pm 0.85$ & $5.74 \pm 0.89$ & $5.96 \pm 0.93$ \\
\hline $13-24$ & $7.17 \pm 1.35$ & $6.75 \pm 0.94$ & $6.97 \pm 1.19$ & $7.38 \pm 1.31$ & $6.88 \pm 0.91$ & $7.14 \pm 1.17$ \\
\hline $25-36$ & $8.43 \pm 1.36$ & $8.08 \pm 0.84$ & $8.27 \pm 1.16$ & $8.58 \pm 1.34$ & $8.27 \pm 0.83$ & $8.44 \pm 1.14$ \\
\hline $37-48$ & $9.83 \pm 1.91$ & $9.48 \pm 1.69$ & $9.65 \pm 1.78$ & $10.02 \pm 1.84$ & $9.77 \pm 1.60$ & $9.89 \pm 1.69$ \\
\hline $49-60$ & $12.14 \pm 3.15$ & $9.68 \pm 1.44$ & $11.05 \pm 2.72$ & $12.76 \pm 3.96$ & $10.3 \pm 1.79$ & $11.67 \pm 3.28$ \\
\hline Total & $7.14 \pm 2.41$ & $6.34 \pm 2.15$ & $6.72 \pm 2.31$ & $7.35 \pm 2.43$ & $6.55 \pm 2.15$ & $6.93 \pm 2.32$ \\
\hline \multicolumn{4}{|c|}{ Table 2. Comparison of Mean Weights of Study Participants at Admission and Discharge } \\
\hline
\end{tabular}

The average duration of stay at the NRCs was $7.81 \pm 4.096$ days, for boys it was $7.78 \pm 4.45$ days and for girls it was $7.86 \pm 4.42$ days. $152(44.05 \%)$ of the children had stayed at the NRC for at least 8 days. A statistically significant difference was found between mean weight at admission and mean weight at discharge for all children who stayed in NRC for more than 8 days. Children who stayed in NRC for $>8$ days up to 14 days accounted for $33.04 \%$ and those $>14$ days were $11.01 \%$. 


\begin{tabular}{|c|c|c|c|c|c|}
\hline $\begin{array}{c}\text { Total Days in } \\
\text { Hospital }\end{array}$ & $\begin{array}{c}\text { Total Children } \\
\text { (N=345) (\%) }\end{array}$ & $\begin{array}{c}\text { Mean Weight at } \\
\text { Admission (Kg) }\end{array}$ & $\begin{array}{c}\text { Mean Weight at } \\
\text { Discharge (Kg) }\end{array}$ & $\begin{array}{c}\text { t } \\
\text { Value }\end{array}$ & $\begin{array}{c}\text { P } \\
\text { Value }\end{array}$ \\
\hline$\leq 3$ days & $55(15.94)$ & $6.56 \pm 2.32$ & $6.62 \pm 2.25$ & -0.957 & $0.343(\mathrm{NS})$ \\
\hline 4-7 days & $138(40)$ & $7.09 \pm 2.13$ & $7.29 \pm 2.18$ & -9.560 & $<0.001$ \\
\hline 8-14 days & $114(33.04)$ & $6.26 \pm 2.23$ & $6.48 \pm 2.20$ & -8.995 & $<0.001$ \\
\hline$>$ 14 days & $38(11.01)$ & $6.99 \pm 2.89$ & $7.42 \pm 2.94$ & -5.150 & $<0.001$ \\
\hline \multicolumn{2}{|r|}{ Table 3. Distribution of Study Participants and their mean Weight According to Total Duration in Hospital } \\
\hline
\end{tabular}

Out of 345 SAM children, majority (98) had diarrhoea, 10 children had measles and next common cause of admission was pneumonia. A few cases had congenital heart diseases like Tetralogy of Fallot, Patent ductus arteriosus, and Ventricular septal defect. Analysis of the available data on followup visits revealed dropout rates of $16.09 \%, 24.91 \%, 28.07 \%$ for three followup visits respectively.

The followup visits after discharge showed a declining trend with less number of children being brought for third followup.

\section{DISCUSSION}

The nutritional rehabilitation centres were established for facility based care of the children with severe acute malnutrition. It caters to the needs of those from 0-60 months of age. They were first established in the state of Madhya Pradesh to reduce the mortality and improve the nutrition of the affected children. The management of SAM children was based on the facility based care of severe acute malnutrition by MOHFW. ${ }^{1}$

The present study showed that out of the total children admitted to NRC, majority of them (36.23\%) were in the age group of 12-23 months. This was comparable to a study by Singh et al wherein about $41.8 \%$ children were in the age group of 12-23 months. 5 The proportion of females (52.17\%) among the admitted children was greater than that of males (47.83\%). Similar finding was reported in a study conducted by Sanghvi J et al who observed that from among 300 malnourished children admitted at an NRC in Indore, females were $52 \%$ as compared to $48 \%$ males. ${ }^{6}$ Hashmi $\mathrm{G}$ et al showed similar findings as our study. ${ }^{7}$

Weight has been taken as the main anthropometric measure of response to treatment. An improvement in the weight of severe malnourished children has the most significant effect in reducing the mortality among them. In the present study, the overall mean weight at admission is $6.72 \pm 2.31 \mathrm{~kg}$ and the overall mean weight at discharge is $6.93 \pm 2.32 \mathrm{~kg}$. A statistically significant difference was found between mean weight at admission and mean weight at discharge for all children ( $t=-11.572 ; \mathrm{p}<0.001)$, for males it was $\mathrm{t}=-8.094 ; \mathrm{p}<0.001$ and for females $\mathrm{t}=-8.257$; $<<0.001$.

Similar findings were observed by Hashmi G et al in Gulbarga study and G. Taneja et al study which showed a statistically significant difference between mean weight at admission and mean weight at discharge for all children. ${ }^{8}$ Contrary to present study, a study done by Rawat et al showed that there were no statistically significant difference between the mean weight at discharge and the mean weight at admission. ${ }^{9}$ Cole craft et al in a study at four day care NRCs also reported a significant increase in weight for age for the admitted children. ${ }^{10}$ The children were on therapeutic diets F75, F100 as starter and catch up formula feeds while in NRC. Older children were given solid feeds like halwa, khichri, etc. Study by Mamidi et al noted a moderate gain in weight among severely malnourished children on using local energy dense foods for nutrition rehabilitation. ${ }^{11}$

The average duration of stay at the NRCs was $7.81 \pm 4.096$ days as opposed to the guidelines of 14 days duration. In a study by Rinki Shah et al, the duration of stay was 16 days while in a study by G Taneja et al, the duration of stay was 14 days. ${ }^{8,12}$ In a study done by Hashmi G et al, it was 7.17 \pm 1.6 days which was comparable to the present study, though it is far less than the standard treatment guidelines of 14 days stay. To achieve a target weight gain of $15 \%$ of the initial weight before discharge, a stay of 14 days with nutrition rehabilitation, micronutrient supplementation is recommended. It was noted in a few studies that there was a weight gain even after a week of stay in NRC. It is challenging to convince parents of SAM children for hospital stay of 14 days. Most of the children come from families of low socioeconomic group/below poverty line. There is a tendency among the parents to go home once the child's appetite improves and starts gaining weight, even though they have not reached the target weight. The reasons are economic constraints and the obligation to take care of other children at home. The health workers need to screen children at primary health centre, subcentres, and on immunisation days all children for SAM using the MUAC tape. The SAM children if identified as sick need to be seen by the medical officer and referred for admission at NRC. To facilitate the same, the health worker needs to accompany them to NRC for admission. Once discharged from the NRC, the information has to be communicated to the concerned health worker, staff of health centre so that there is compliance for followup visits.

The data analysis revealed dropout rates of $16.09 \%$, $24.91 \%$ and $28.07 \%$ for three followups respectively. The dropout rates increased from first to third followup. NRC is located in a tertiary care centre, where most of the cases were either brought directly or referral from others to the centre for complications. For them it may be too far from home and may be a financial burden to attend followup, so there is no compliance for followup visits. These findings were consistent with studies by G Taneja et al, and Rao BR et al.8,13 In a study by Ratnamanjula et al, defaulter rate was $30 \%$, the reasons being loss of employment and the obligation to take care of other children at home, etc. ${ }^{14}$

Prevention of malnutrition by educating the community about the infant and young child feeding practices will be of great value. 15 The most common comorbid conditions associated with SAM were acute gastroenteritis (41.45\%) followed by acute respiratory tract infections (10.15\%). In a study by Naik $\mathrm{S}$ A et al, from among 146 children admitted with SAM, 30\% suffered with acute gastroenteritis followed by $26.3 \%$ with acute respiratory tract infections. ${ }^{16}$ As diarrhoea and pneumonia are the common causes of mortality and morbidity in children under 5 yrs., more so in SAM children as noted in the present and other studies, preventive measures like improving nutrition, hygiene, immunisation will pave way for better health care. 


\section{CONCLUSION}

There was a statistically significant weight gain among SAM children treated at NRC, objectively demonstrated by comparing the weight at admission and discharge.

Nutritional rehabilitation centre has an impact on improving the nutritional status of SAM children. To improve the utilisation of the NRC services, there should be better coordination and communication between the health workers and the staff of NRC units. Further, the SAM child should be followed up in the community, if there is noncompliance for followup visits in NRC. Though the stay at NRC is for 14 days ideally, in practice it does not find favour among the parents who happen to be from the low socioeconomic group. Once the medical complications are managed with and the appetite of the child improves, shifting these children to a community based programme may go a long way in motivating parents to propagate and utilise services of NRC. The common comorbid conditions to some extent be prevented through better compliance and coverage of childhood immunisation, personal and environmental hygiene.

\section{Limitation of the Study}

Limitation being non-availability of data on outcome of SST. Abbreviations: NRC- Nutrition Rehabilitation Centres, SAMSevere acute malnutrition, MUAC - Mid upper arm circumference, SST - Supplementary suckling technique.

\section{REFERENCES}

1. Ministry of health and family welfare, government of India. Operational guidelines on facility-based management of children with severe acute malnutrition. New Delhi, India: government of India 2011.

2. Community based management of severe acute malnutrition. A joint statement by the World Health organisation, the World Food Programme, the United Nations System Standing Committee on Nutrition and United Nations Children's Fund 2007.

3. Arnold F, Parasuraman S, Arokiasamy P, et al. Nutrition in India. National Family Health Survey (NFHS-3) India. International Institute for population science. Deonar, Mumbai 2005-06.

4. Press information bureau. Nutritional rehabilitation centres. Ministry of health and family welfare. Government of India. available from: pib.nic.in/ newsite/ printrelease. aspx?relid=121407.

5. Singh K, Badgaiyan N, Ranjan A, et al. Management of children with severe acute malnutrition: experience of nutrition rehabilitation centers in Uttar Pradesh, India. Indian Pediatr 2014;51(1):21-5.
6. Sanghvi J, Mehta S, Kumar R. Predicators for weight gain in children treated for severe acute malnutrition: a prospective study at nutritional rehabilitation center. Article ID 808756, ISRN Pediatrics 2014;2014:1-5.

7. Hashmi G, Kumar SS. Evaluation of the effects of nutrition intervention measures on admitted children in nutritional rehabilitation center, Gulbarga, India. Int J Community Med Public Health 2016;3(9):2550-4.

8. Taneja G, Dixit S, Khatri AK, et al. A study to evaluate the effect of nutritional intervention measures on admitted children in selected nutrition rehabilitation centres of Indore and Ujjain divisions of the state of Madhya Pradesh (India). Indian journal of Community Medicine 2012;37(2):107-15.

9. Rawat R, Marskole P. A study to evaluate the effect of nutritional intervention measures on children with severe acute malnutrition admitted in nutrition rehabilitation center at civil hospital Bairagarh, Bhopal, Madhya Pradesh. Journal of Evolution of Medical and Dental Sciences 2015;4(17):2937-42.

10. Colecraft EK, Marquis GS, Bartolucci AA, et al. A longitudinal assessment of the diet and growth of malnourished children participating in nutrition rehabilitation centres in Accra, Ghana. Public Health Nutrition 2004;7(4):487-94.

11. Mamidi RS, Kulkarni B, Radhakrishna KV, et al. Hospital based nutrition rehabilitation of severely undernourished children using energy dense local foods. Indian pediatrics 2010;47:687-93.

12. Shah RH, Javdekar BB. Management of children with severe acute malnutrition: experience of nutrition rehabilitation centre at Baroda, Gujarat. Int J Contemp Pediatr 2014;1(1):3-6.

13. Rao BR, Naidu SA, Kumar LS, et al. Effectiveness of nutritional intervention measures on children admitted in nutritional rehabilitation center (NRC), King George Hospital Visakhapatnam. J Evid Based Med Healthc 2015;2(60):9009-11.

14. Manjula MR, Nirmala C, Nethagani S, et al. Outcome study of NRC in Andhra Pradesh. J Evolution Med Dent Sci 2016;5(64).

15. Paul GP, Nayak MSDP. Effect of nutritional intervention in undernourished children at nutritional rehabilitation centre, Ongole, Andhra Pradesh. IOSR Journal of Dental and Medical Sciences 2016;15(6):20-3.

16. Syed TA, Naik SA, Wasim RA, et al. Demographic, clinical profile of severe acute malnutrition and our experience of nutrition rehabilitation centre at children hospital, Srinagar, Kashmir. Int J Contemp Pediatr 2015;2(3):233-7. 